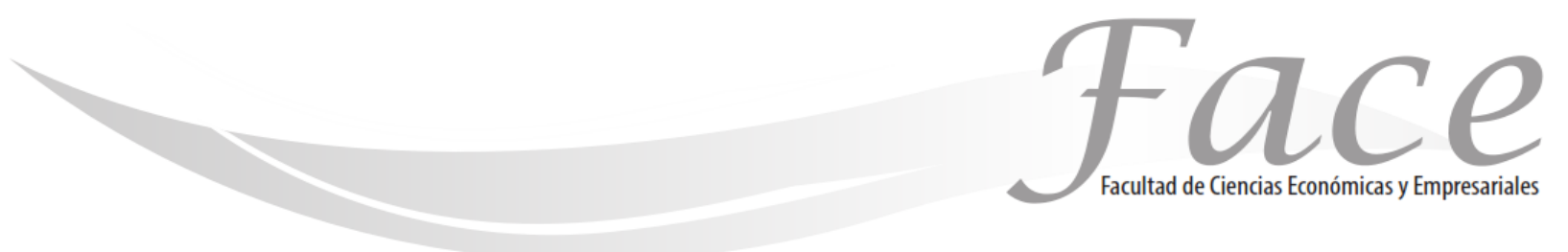

ISSN Impreso: 1794-9920

ISSN Electrónico: 2500-9338

Volumen $19-\mathrm{N}^{\circ} 2$

Año 2019

Págs. $90-103$

(c)

\title{
TRADICIÓN E INNOVACIÓN DEL PAN ARTESANAL DE ACÁMBARO, GUANAJUATO MÉXICO
}

\author{
Carolina de Jesús Mandujano Sandoval * \\ ORCID: https://orcid.org/0000-0002-1566-0074 \\ Perla Shiomara del Carpio Ovando ** \\ ORCID: https://orcid.org/0000-0002-4907-783X
}

Fecha de Recepción: Agosto 7 de 2019

Fecha de Aprobación: Noviembre 4 de 2019

\section{Resumen:}

Este artículo analiza los retos y dificultades en torno a la elaboración y comercialización de la elaboración de pan en el municipio de Acámbaro, Guanajuato. Para cumplir el objetivo se acudió a la metodología cualitativa de tipo etnográfica. El trabajo de campo se realizó durante el periodo junio-diciembre 2015 y enero-octubre de 2016 (para la obtención de entrevistas a panaderos y a diferentes actores vinculados con la producción de pan). La información del trabajo de campo permite analizar antecedentes históricos del pan de Acámbaro, su comercialización, las principales dificultades del gremio, las estrategias que han tenido que desarrollar quienes se dedican a la elaboración artesanal, semi-industrial y totalmente industrial. Se requieren mayor capacitación respecto a materias primas, comercialización, acceso a créditos y cuidado ante los riesgos a la salud por dedicación al oficio. Quienes trabajan en panificadoras han señalado dificultades como los horarios de la jornada de trabajo, el incremento del precio de los productos, la competencia con otros productores y necesidad de capacitación constante.

Palabras clave: Pan, consumidores, desarrollo, cultura.

${ }^{* *}$ Docente-investigador, Licenciada en Desarrollo Regional, Universidad de Guanajuato, Contacto: carito_isai@hotmail.com

Docente-investigador, Profesora investigadora Universidad de Guanajuato, Contacto: shiomarartesania@gmail.com. 


\title{
TRADITION AND INNOVATION OF ARTISAN BREAD FROM ACÁMBARO, GUANAJUATO MEXICO
}

\begin{abstract}
:
Este artigo analisa os desafios e as dificuldades em torno da elaboração e comercialização da panificação no município de Acámbaro, Guanajuato. Para atingir o objetivo, foi utilizada a metodologia qualitativa do tipo etnográfico. $O$ trabalho de campo foi realizado no período de junho a dezembro de 2015 e janeiro a outubro de 2016 (para obter entrevistas com padeiros e diferentes atores relacionados à produção de pão). As informações do trabalho de campo permitem analisar antecedentes históricos do pão de Acámbaro, sua comercialização, as principais dificuldades da aliança, as estratégias que tiveram para desenvolver aqueles dedicados à elaboração artesanal, semi-industrial e totalmente industrial. É necessário mais treinamento sobre matérias-primas, marketing, acesso a créditos e atendimento de riscos à saúde devido à dedicação ao comércio. Quem trabalha em padarias apontou dificuldades como o horário de trabalho, o aumento do preço dos produtos, a concorrência com outros produtores e a necessidade de treinamento constante..
\end{abstract}

Keywords: Bread, Consumers, Development, Culture.

\section{PESQUISA CIENTÍFICA, GRUPOS ACADÊMICOS E REDES DE PESQUISA}

Resumo:

Este artigo analisa os desafios e as dificuldades em torno da elaboração e comercialização da panificação no município de Acámbaro, Guanajuato. Para atingir o objetivo, foi utilizada a metodologia qualitativa do tipo etnográfico. $O$ trabalho de campo foi realizado no período de junho a dezembro de 2015 e janeiro a outubro de 2016 (para obter entrevistas com padeiros e diferentes atores relacionados à produção de pão). As informações do trabalho de campo permitem analisar antecedentes históricos do pão de Acámbaro, sua comercialização, as principais dificuldades da aliança, as estratégias que tiveram para desenvolver aqueles dedicados à elaboração artesanal, semi-industrial e totalmente industrial. É necessário mais treinamento sobre matérias-primas, marketing, acesso a créditos e atendimento de riscos à saúde devido à dedicação ao comércio. Quem trabalha em padarias apontou dificuldades como o horário de trabalho, o aumento do preço dos produtos, a concorrência com outros produtores e a necessidade de treinamento constante.

Palavras-chave: Pão, Consumidores, Desenvolvimento, Cultura. 


\section{INTRODUCCIÓN:}

Sobre la historia de las acambaritas Múltiples son los elementos que construyen la identidad cultural del municipio de Acámbaro (al sur del estado de Guanajuato), pero ninguno más popular y famoso que su producción de pan. Tan destacada es ésta que, dentro de los lugares de la región, Acámbaro sobresale por su variedad de panes, sus sabores y texturas.

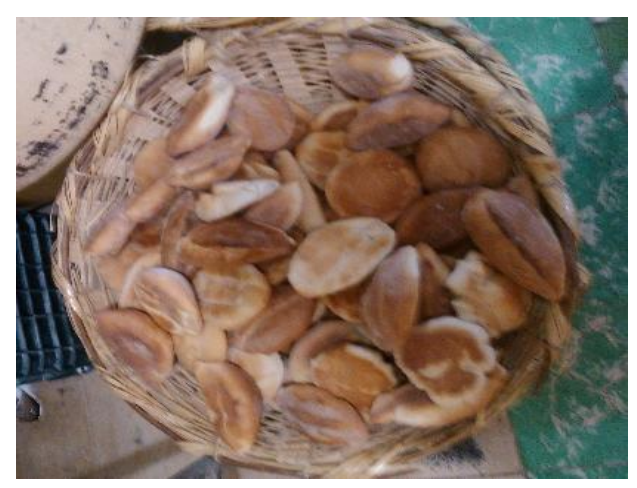

Fotografía 1: Canasto con piezas de telera y bolillo. 1

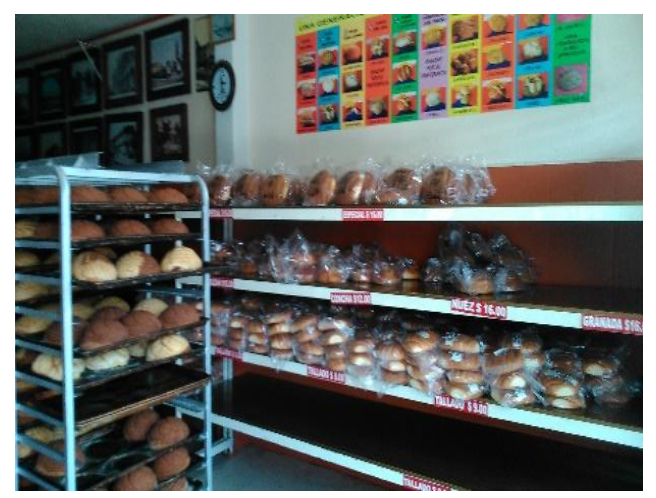

Fotografía 2. Establecimiento donde se vende el tradicional pan de Acámbaro.

\section{MATERIALES Y MÉTODOS:}

Para aproximarnos al estudio de esta actividad productiva valiosa cultural y económicamente para el municipio, en esta investigación se acudió a una metodología cualitativa de tipo etnográfica, cuyas técnicas han sido: observación participante, entrevistas semiestructuradas, revisión documental y obtención de material audiovisual. Se realizaron 21 entrevistas en el municipio de Acámbaro (personas dedicadas al oficio de realizar pan artesanal, a empleados y a dueños de panificadoras). La información obtenida en el trabajo de campo permitió la construcción del contenido que aquí se presenta

\section{RESULTADOS:}

Respecto a los antecedentes históricos del pan de Acámbaro, por ejemplo, los testimonios obtenidos nos comparten los orígenes de las famosas acambaritas (pan famoso en el lugar) y señalan que Noé Rosas, un panadero de abolengo, fue el inventor de las famosas acambaritas (de chocolate, canela, fresa y vainilla). Ejerce el oficio desde 1960 y comenzó a los 16 años. Un panadero subraya: Fui el primero que hice las acambaritas en Celaya donde trabajaba. Ya cuando se cambiaron mi tío Samuel y la familia Loeza, para Acámbaro, empezamos a hacer las acambaritas (Lujano, 01 de noviembre de 2015, panadero).

Otro experto en el oficio también subraya que las acambaritas fueron creadas en Celaya por Don Noé Rosas, originario de Acámbaro, quien trabajó en la panadería "El Triunfo" y que actualmente tiene la panificadora "La Casa del Buen Pan". Y sigue indicando que: El hecho ocurrió porque al estar elaborando panes grandes como tallado, picones, ranchero, etc., le sobró un pedazo de masa e hizo pequeñas bolas, que al cocerse resultaron panzoncitas, de ahí el origen de las acambaritas (Gerardo, 01 de noviembre de 2015, 61 años, panadero).

\footnotetext{
${ }^{1}$ Las fotografías que ilustran este documento corresponden al archivo fotográfico de la autora de esta investigación.
} 
Mauricio Ortigosa Hernández

Otros señalan que estas particulares y distintivas piezas de pan, de igual manera fueron creadas en Celaya ${ }^{2}$, pero por un señor de nombre Samuel Silva. Testimonios como el del panadero Julio, señalan que: Bueno, el origen de la historia, ésa sí se remonta a aquí a Acámbaro. (...) Se me hace que han de haber sido los hermanos Loeza, si no me equivoco. Ellos por casualidad les salió la acámbara, que se les vino la revoltura, se les hizo volumen mucho y, entonces, el señor dice ¿Y ahora qué hacemos con esto? Entonces la volvieron a meter a la máquina, le dieron otras pasadas y de ahí empezaron a hacer puras bolitas, las metieron al horno y vieron que salieron muy bonitas $y$ buenas, con buen sabor. Ése fue el origen de la acámbara, sí (Julio, 02 de noviembre de 2015, 47 años, panadero, Acámbaro).

También hay quienes en tono anecdótico señalan que: Haciendo pan grande un niño quiso imitar a sus papás, quienes se encontraban elaborando pan, entonces, tomó un pedazo de la masa y queriéndolo hacer como el pan grande, los puso en la charola, en forma de bolitas. Se olvidó de ellas y continuó jugando; después de un rato unos de los panaderos las metió a hornear percatándose de que las había hecho el niño, las probaron y así fue como nacieron las acambaritas, solo que ya con una forma más definida y mejorada (Manuel, 03 de noviembre de 2015, 47 años, panadero, Acámbaro).

Primero les llamaban papas, después acambareñas y ahora ya son acambaritas (Pablo, 03 de noviembre de 2015, 48 años, panadero, Acámbaro). Son, pues, diferentes las versiones las que en Acámbaro podemos encontrar respecto al origen de las famosas acambaritas. Otras fuentes indican que una de las panificadoras que desde hace 81 años ha mantenido su receta es El Triunfo, empresa que surgió en 1935 con la familia Silva Loeza, familia que se distinguió por crear la fórmula de las acambaritas.

Fotografía 3: Pan grande tradicional y cajas de galletas, en la $6^{a}$ Feria de la Panificación, Acámbaro, Guanajuato.

Súbrayese que también podemos encontrar habitantes, consumidores y hasta hacedores, que desconocen detalles de los orígenes históricos del pan del municipio. Pues no lo conozco muy bien, pero yo creo que, como que es para economizar o darle a una familia completa una

\footnotetext{
${ }^{2}$ El municipio de Celaya está asentado en un valle del Bajío mexicano, rodeado de cerros, lo que lo hace propicio para la agricultura y ser uno de los más productivos en la región e incluso en el estado de Guanajuato. Además, Celaya es conocida como la Puerta de Oro del Bajío, gracias al desarrollo económico que propicia en su región (Larios-Gómez et al, 2015).
}

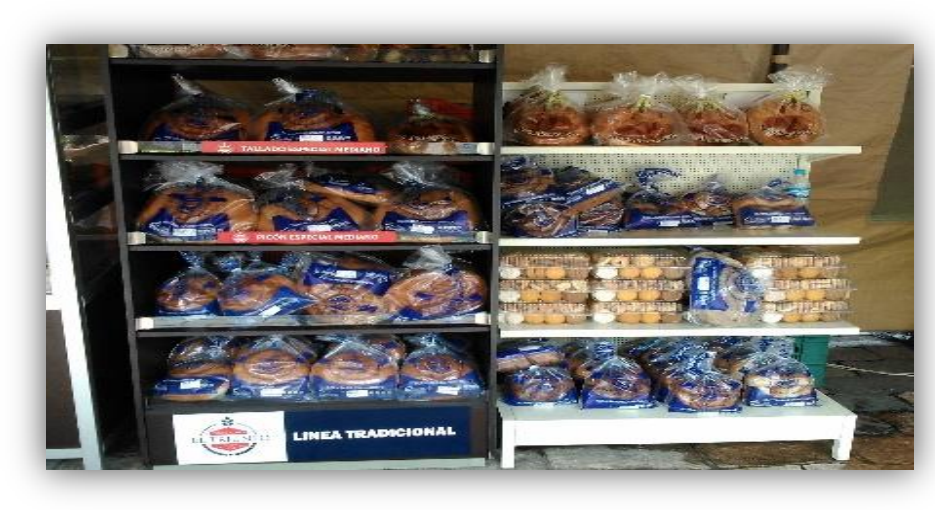

bolsita y se hicieron pedazos más chiquitos en vez de partir un pan grande, pues, se parten, se dan panes chiquitos y siguen siendo de Acámbaro. Y ahora pues se hicieron muy tradicionales, porque donde quiera que uno sale, te preguntan por las acambaritas (Lourdes, 56 años, jubilada, Péjo, Salvatierra). No sé muy bien de la historia de las acambaritas, pero yo siento que el nombre lo dice ¿No? acambaritas: Acámbaro (Mariana, 52 años, comerciante, Ciudad de México).

Respecto al pan grande de Acámbaro diversas fuentes indican que surgió cuando los primeros franciscanos llegaron a la región y les enseñaron a la comunidad el arte de la panadería. Fue desde mediados del siglo XX que surgieron negocios que siguen actualmente produciendo los panes con la misma receta (Castro, 2016). Quienes se dedican a este oficio y fueron entrevistados en este estudio, informan que tienen entre 25 y 50 años dedicándose a la producción del pan y les preocupa que los jóvenes no estén interesados en aprender el oficio. Respecto al tiempo dedicado al oficio, algunos testimonios indican: Ya tengo, pues yo creo que más de la mitad de mi vida, yo creo unos 25 años, si no es que más (Julio, 47 años, panadero, Acámbaro). Desde hace 50 años (me dedico a hacer pan) (Valentín, 64 años, panadero, Acámbaro).

$Y$ respecto a los motivos que consideran mantienen viva la tradición panadera en el municipio señalan aspectos como los que se presentan en el diagrama siguiente: 


\section{Diagrama 1.}

Motivos para la permanencia de la tradición panadera

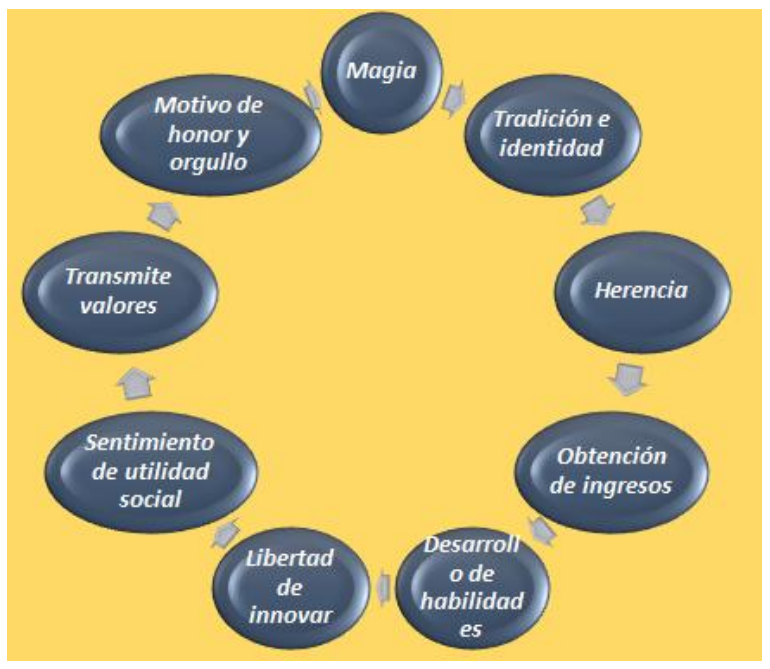

Fuente: Elaboración propia a partir de información obtenida en trabajo de campo.

Materia prima y objetivos que persigue la elaboración de pan Respecto a las materias primas con la que trabajan las panaderías acambarenses hay que señalar que son adquiridas, en su mayoría, con proveedores externos, que las llevan a Acámbaro; aunque también hay testimonios que indican que se compran a vendedores internos y señalan: Pues nosotros la compramos aquí, porque aquí está una tienda en el centro, donde a nosotros nos surten (...) (Elia, 63 años, panadera, Acámbaro).

Las panaderías pequeñas son las que, por lo regular, sí compran aquí mismo todo lo que necesitan para su producción (Antonio, 33 años, panadero, Acámbaro). También nos dejan saber que los principales lugares de los que provienen las materias primas, son: Michoacán, Ciudad de México, Querétaro, Estado de México, Maravatío, Celaya y el propio municipio de Acámbaro. Sobre los objetivos de la realización de este producto indican que el principal es la comercialización. No, pues, (se realiza) para comercializarlo, ya pues me llevo una 0 dos piezas para autoconsumo (Carlos, 65 años, panadero, Acámbaro). Pues una parte es para la familia, o sea, una parte, no toda. Lo demás es para comercializar (Julio, 47 años, panadero, Acámbaro).

Sobre la cantidad en piezas diariamente producidas por los establecimientos, señalan que suelen ser variable, dependiendo de distintos factores, tales como: el tamaño y la ubicación del negocio o la empresa panificadora, de los empleados con que cuente, así como de las temporadas o épocas del año. En la panificadora "El Triunfo", por ejemplo, se realizan de dos mil a tres mil piezas de pan diarias; manejando panes de diversos tamaños, desde los 50 gramos, hasta un kilo 600 gramos (Larios, 07 de julio de 2014).

Por otra parte, la panificadora Tío Sam, actualmente produce tan solo de acambaritas, alrededor de 4 mil piezas al día (Castro, 17 de mayo de 2016, panadero). Quinientas, miles, sí, son muchas piezas (las que producen) (Valentín, 64 años, panadero, Acámbaro). Mira solamente de pan de sal, yo pienso que te hago como unos, espérame, son ocho, ochocientos, $5 \times 8=40$, cuatro mil, solamente de bolillo son cuatro mil, de puro bolillo y conchas serán otras mil. Del pan fino serán como tres mil; más aparte el pan grande, la cema, la acambarita. Un promedio, ponle unas ocho mil piezas diarias (Gerardo, 61 años, panadero, Acámbaro).

Las piezas elaboradas en las panaderías van desde 350 piezas hasta las 10 mil aproximadamente. Como se mencionó con anterioridad, la elaboración de pan varía de lugar, del número de empleados, de la demanda del producto, de la temporada del año, etc.

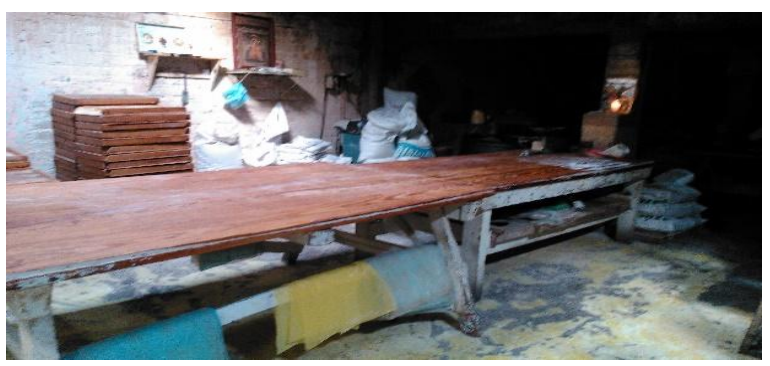

\section{Fotografía 4: Mesa de trabajo de los panaderos} artesanales.

En seguida se muestra un diagrama con los principales tipos de pan y piezas que son de mayor preferencia para los consumidores. 
Mauricio Ortigosa Hernández

\section{Diagrama 2. Panes de mayor preferencia}

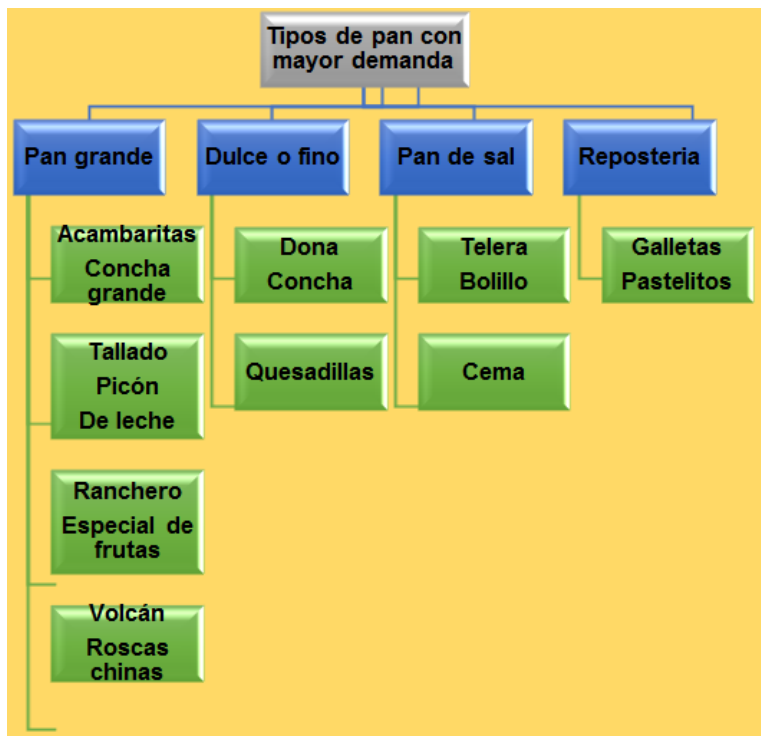

Fuente: Elaboración propia a partir de información obtenida en trabajo de campo.

\section{Comercialización del producto}

Los compradores del pan en Acámbaro suelen provenir de comunidades y colonias del propio municipio, de otras localidades y también de otros estados, también se comercializa en Estados Unidos. Algunos habitantes de Acámbaro señalan que se compra para consumo familiar, para obsequiar o para revender. Pues (vienen) de muchas partes, local y externa pues, de otras ciudades también; de hecho sí se reconoce al pan de Acámbaro en otros lugares, como en el Estado de México (Alan, 30 años, empleado, Acámbaro). Vienen los turistas y uno lo consume aquí, y pues de comunidades también, de todo tipo (Karem, 46 años, dedicada a las actividades del hogar, Acámbaro). Viene gente de todos lados, incluso, de Estados Unidos, gente de fuera, este pan ha salido hasta internacionalmente. Ha sido famoso, a nivel nacional e internacional (Pedro, 55 años, panadero, Acámbaro). Viene mucha gente que me pide pan, ahorita tengo un pedido, que se va no sé a dónde, a México de puro pan grande. Hay viene gente que ahorita me acaba de decir otro señor que lo regala porque viene de México y se acabaron las vacaciones y para el miércoles quiere 100 piezas, 100 bolsas de acámbaras y los hijos lo vienen a comprar (Gerardo, 61 años, panadero, Acámbaro).
La difusión del producto se ha hecho desde los propios consumidores, de la publicidad en la televisión local, en periódicos y en internet (redes sociales).También los expendios de pan y los mercados de otros municipios son quienes recomiendan el producto. Lo anterior hace que el pan sea motivo para atraer al visitante.

\section{La unión hace la fuerza}

Como indica Castro (2016), en 1993 los panaderos crearon la Unión de Productores de Pan Grande de Acámbaro. El presidente de dicho organismo comentó que una de las razones para la unión fue registrar y proteger las marcas surgidas. La sociedad civil se constituyó con la introducción de 12 panaderías e hicieron diversos intentos para obtener la región de origen sin lograrlo. Fue hasta 2011 que los productores tomaron de nuevo impulso para lograr dicho objetivo. Hubo cambios en la sociedad, se creó un consejo regulador para la creación de normas y lineamientos para cuidar y mantener la calidad del pan grande. Indica Castro (2016) que así empezaron a tener el reconocimiento del Gobierno y obtuvieron ayuda para registrar la marca como región de origen en el Instituto Mexicano de la Propiedad Industrial (IMPI).

En entrevista al presidente de la Unión, él señala: "Nos ayudaron para que el IMPI reconociera la zona geográfica. Fuimos la primera marca colectiva en el Estado" (Daniel Casas en entrevista con Castro, 17 de mayo de 2016). Por un año, la Unión de Productores realizó las reglas de uso, los estándares de calidad y de producción que se debían cumplir para elaborar el pan. Fue en mayo del 2014 que recibieron la licencia Marca Colectiva Pan Grande de Acámbaro Región de Origen (otorgada por el IMPI) y ésta fue la primera en Guanajuato. En el registro se integraron 13 empresas de Acámbaro y se certificaron nueve tipos de pan: acambaritas, pan tallado, picón, granillo, ranchero, pan de muerto, cema, pan de agua y leche.

Uno puede estar dentro de la Unión, pero quizá no pueda entrar en la Marca Distintiva. Esto nos obliga a nosotros, como productores, a ser más competitivos. No todas las panaderías pueden portar el sello porque no tienen los lineamientos (Daniel Casas García, Presidente de la Unión de Productores de Pan Grande de Acámbaro, en entrevista con Castro, 17 de mayo de 2016). De acuerdo con el Inegi, indica Castro (2016), en Acámbaro se encuentran 54 panaderías, 20 de ellas se enfocan al pan tradicional del municipio; además del $80 \%$ de la producción del pan se vende fuera de la región y este sector genera alrededor de 490 fuentes de empleos directos.

La apertura de negocios de pan, su transportación y venta en diversas partes fuera del municipio ha logrado difundir el famoso pan grande y al propio municipio. De acuerdo 
con Islas (2014) y Castro (2016), actualmente se encuentra entre un $20 \%$ y $25 \%$ la cantidad de producción local de pan que se queda en Acámbaro, y de un $75 \%$ a un $80 \%$ la que se vende fuera de la región. Siendo esta última mayor, que la que se queda en la ciudad para comercialización interna. Son varias las panaderías que comercializan el producto fuera del municipio, algunas de ellas son: a) Panificadora Loeza, distribuye sus panes en los municipios de Salvatierra, Celaya, Coroneo, Salamanca, Cortázar e Irapuato, y en los estados de Michoacán y Querétaro. b) El Triunfo comercializa sus productos a través de tiendas de autoservicio, en distintos municipios del estado, como Querétaro, Michoacán y la Ciudad de México, y c) Panificadora Tío Sam comercializa sus panes tradicionales en 19 sucursales, 8 de las cuales se ubican en Acámbaro y las demás en Chupícuaro, Coroneo, Salvatierra, Moroleón, Yuríria y Querétaro; teniendo también presencia en Celaya, Apaseo El Grande, León, Silao, Guanajuato capital y en la Ciudad de México (Castro, 17 de mayo de 2016). en varias partes, en varias partes. Te puedo nombrar muchas, pero no, no acabaría (Gerardo, 61 años, panadero, Acámbaro). Pues sí, yo estuve trabajando en Estados Unidos y allá hay panaderías que elaboran pan parecido, pero obvio no es igual verdad, cambian a veces la calidad de las harinas, o de grasas vegetales (Pablo, 48 años, panadero, Acámbaro).

El pan está viajando hoy mucho más que antes, refiere Aguado (2014), no solo a través de la venta que hacen sus productores en cada una de las distintas partes; sino también se aprovechan exposiciones internacionales para que éste sea promocionado y se aprecie, no solo como un producto tradicional sino también regional, lo que implica una suma de características físicas que lo hacen diferente al pan que se hace en otros lugares. Como ya se ha dicho, el pan de Acámbaro fue el primer producto que obtuvo la licencia Marca Colectiva de Pan.

Diagrama 3. Ciudades donde se comercializa pan de Acámbaro

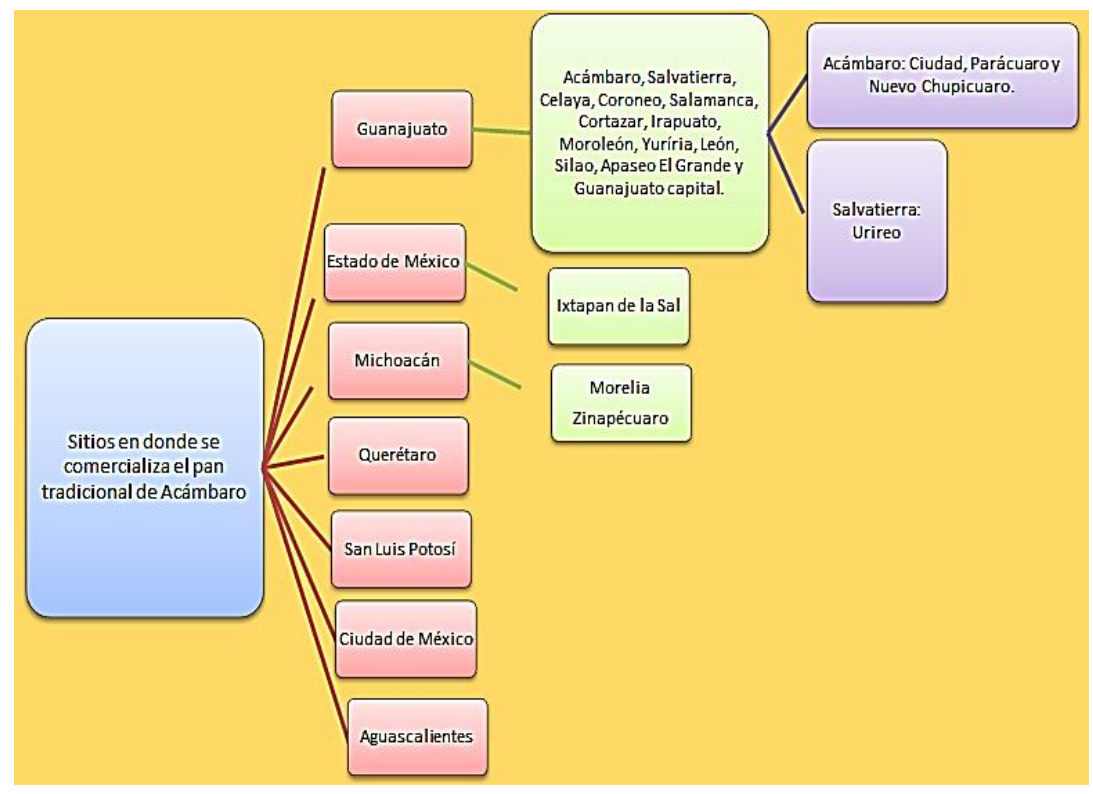

Fuente: Elaboración propia a partir de información obtenida en trabajo de campo.

Hay quienes afirman que también se comercializa en Estados Unidos: Pues claro, porque por ejemplo mira en Los Ángeles, hay una panadería que dice Pan de Acámbaro. Quién lo hace, desconozco; pero sí hay los mismos que se van de aquí, los contratan, se los llevan, le pagan todo. Y tú sabes que es un pan que te abre las puertas donde quiera. Entonces hay pan de aquí de Acámbaro, en Celaya, en Querétaro, Ixtapan de la Sal, no
Fue la primera marca colectiva en el estado de Guanajuato y actualmente se oferta el producto en lugares donde el gobierno del estado presenta y comercializa los productos con el distintivo de Marca Colectiva.

\section{Modernización en el proceso de elaboración}

Las personas dedicadas a este oficio indican que anteriormente el proceso de elaboración de pan era 
Mauricio Ortigosa Hernández

únicamente artesanal; la revoltura era a mano; aplicando una cocción preferentemente con leña, en un horno conocido como calabacero (hecho de piso, barro y piedra), en hojas de lámina. Era calentar el horno con leña, se sacaba la leña, se quedaban las brasas, era lo que hacía, pero no era la cantidad que se hace ahora de pan (Gerardo, 61 años, panadero, Acámbaro);

El proceso, en general, tardaba de tres a cuatro horas y debido a su modo de preparación y a la utilización de ingredientes totalmente naturales se dice que el pan tenía más y mejor sabor que el actual. El proceso de preparación ha tendido a modificarse con el transcurso del tiempo, puesto que algunas panaderías han optado por modernizar y tecnificar su proceso; sin embargo, hay quienes siguen conservando ciertas características de esa elaboración detallada y laboriosa. Antonio, un panadero de 33 años, indica que depende de cada negocio o empresa, introducir 0 no algún tipo de maquinaria, ya que actualmente hay tecnología que se puede implementar para la producción del pan, pero básicamente depende del recurso económico con el que se cuente y de la visión de cada productor. Hay quienes opinan también que: Se puede decir que se está perdiendo la tradición para preparar pan; ya ahorita todo es por kilos, por gramos, por todo, y antes no se hacía eso. Antes se preparaba puro puños, a mano y pruébale a ver que le falta y así (Carlos, 65 años, panadero, Acámbaro). Nosotros no hemos hecho cambios, nosotros no, pero pues otras gentes pues sí, hornos turbo, así, nosotros todavía estamos a la antigüita, tenemos nuestro horno de tabique (Elia, 63 años, panadera, Acámbaro). Lo que pasa es que mira, nosotros como te decimos, tenemos una tradición antigua de trabajar, no nos hemos modernizado en tener ni control de salida, verdad, así que digas tú esta todo por computadora, que pones el pan, lo escanean y todo (Esposa de Gerardo, 61 años, panadero, Acámbaro).

Algunos de los principales cambios que se han hecho, en la producción del pan de la localidad en distintas panificadoras, se refiere a la cocción. Actualmente se realiza en hornos calabaceros pero con gas en lugar de leña, en hornos turbo o metálicos; también se han implementado el uso de charolas, los sistemas de control de salida y entrada de las piezas de pan por computadora y escáner; y el uso de máquinas revolvedoras y refinadoras, entre otros mecanismos tecnológicos e industriales. Esto ha ocurrido debido a la demanda del producto. Ahora el pan se elabora con más rapidez a modo de que hay levaduras más fuertes, más débiles y eso influye mucho en la elaboración de un pan, se acelera más el proceso y el cocimiento del horno también (Julio, 47 años, panadero, Acámbaro). Antes no teníamos ese tipo de máquinas, que se llaman refinadoras, entonces, cuando mi abuelito era panadero, lo sobaban (la masa) aquí en la mesa sí. Se le meten lo que es esto de los brazos a la masa para refinarla y después trajeron unas bastoneras; se toman pedazos como de todo esto junto así y a puro brazo para refinarlas eran de rodillos hacia abajo, y estas pues ya le pone uno la masa y ya refina sola (Pablo, 48 años, panadero, Acámbaro).

A pesar de la utilización de herramientas mecanizadas, como las ya mencionadas, se cuida el toque artesanal dentro de la elaboración del pan, puesto que se realiza sin que ello afecte el carácter esencialmente manual del trabajo y del proceso de producción, siguiendo la ejecución de la receta tradicional (CCI \& OMPI, 2003). Como se ha señalado, la elaboración de pan ha sido un oficio que desde sus orígenes ha sido artesanal, sin embargo, con el paso del tiempo, la competencia y la demanda del producto, han provocado que en su elaboración se acuda a mecanismos industriales o semiindustriales. La presencia de máquinas revolvedoras, refinadoras y hornos industriales han tenido que implementarse debido al aumento en la demanda del producto y para facilitar la preparación de la panificación. Pese a ello, la elaboración artesanal ha permanecido, por el gran arraigo cultural que existe en la sociedad. Como indica el Centro de Comercio Internacional (CCl) y la Organización Mundial de la Propiedad Intelectual (OMPI, 2003): "Utilizan herramientas mecanizadas 0 incluso maquinaria, sin que ello afecte el carácter esencialmente manual del trabajo y del proceso de producción" (p. 7).

\section{Dificultades que enfrenta el gremio panadero}

Como se ha señalado, en Acámbaro podemos observar pequeños negocios en los que se realiza pan de forma totalmente artesanal y lugares en los cuales se realiza solamente una parte del proceso de forma artesana e incrementa el uso de medios mecánicos para la elaboración de diversos panes. A la producción de panes en serie, generalmente por medios mecánicos se le conoce como panificación. Esta forma de hacer pan incrementa cada vez más en el municipio. Por ello el consumidor tiene múltiples opciones de dónde adquirir los panes de su preferencia. Sin embargo, esta diversidad de espacios que ofertan pan representa, para quien realiza este oficio artesanal, una amenaza ya que compite no solo con gran cantidad de personas dedicadas a este oficio sino que también debe competir y coexistir con una producción tecnológica, es decir, con múltiples panificadoras que realizan pan a gran escala. En este sentido, debe subrayarse que quizá no pueden competir en cantidad aunque sí en calidad.

Otro problema al que hacen referencia quienes realizan pan en el municipio de Acámbaro, es la competencia desleal. $Y$ es que indican que en exposiciones y ferias artesanales hay sitios en los que se ofrecen panes que se 
presentan como provenientes del municipio, pero no lo son. En todos lados tenemos la competencia desleal. Hay veces, por ejemplo, (...) que en algunas ferias que presentan el pan de colores, unos rosas, unos amarillos, y esos no son de aquí, esos no son pan de Acámbaro y así lo hacen mencionar. Luego dicen: ¡Coma pan de Acámbaro! $Y$ ese no es pan de Acámbaro, el pan de Acámbaro no es así (Miriam, 48 años, coordinadora del patrimonio cultural, Acámbaro).

También consideran que para los locales establecidos de panificación disminuyen sus posibilidades de comercializar cuando existen muchos vendedores ambulantes del mismo producto. Lo único malo son los vendedores ambulantes, es lo que lastima la economía y un negocio que está establecido pagando impuestos, pagando seguro de sus empleados (Julio, 47 años, panadero, Acámbaro).

Otro de los problemas del gremio es la necesidad de capacitación del personal de quienes laboran en panificadoras, se requiere capacitación en elaboración del producto, estrategias de comercialización, programas de apoyo en forma de créditos, optimización de materias primas, inocuidad y, especialmente, respecto al cuidado de la salud de quienes se dedican a la elaboración de pan (de forma artesanal o tecnificada). Debe subrayarse también que el trabajo que realizan los grandes maestros artesanos o quienes acuden a mecanismos tecnológicos para su elaboración, especialmente los primeros, dedican horas de trabajo y dedicación a la realización de pan. Al considerar que los precios que solicitan los artesanos se basan generalmente en los costos del material y el trabajo, el tiempo y esfuerzo de quienes en Acámbaro elaboran pan, debe señalarse que éstos no son compensados por los ingresos económicos que su oficio les reporta, tampoco por la valoración social de su trabajo.

Existen excepciones, podemos encontrar a grandes maestros panaderos provenientes de familias que muchas generaciones se han dedicado a la elaboración de pan y cuyos saberes y calidad del producto los ha llevado a gozar del prestigio y reconocimiento local y regional. Aunque esto no es una constante, existen quienes realizan pan artesanal y tal como lo señala el $\mathrm{CCl}$ y la OMPI (2003): "Los precios que piden los artesanos se basan generalmente en los costos del material y el trabajo, si bien unos cuantos artesanos pueden exigir precios superiores porque gozan de una buena reputación" (p. 7).

Al reflexionar sobre los retos que enfrenta este gremio, debe también señalarse que el desapego e incluso rechazo a las prácticas tradicionales (como elaborar pan artesanal) por parte de las generaciones jóvenes representa que caigan en desuso prácticas de antigua raigambre. Que disminuyan jóvenes dedicados a los oficios artesanales se debe, en el municipio, a diversas razones. Una de ellas es que el estado de Guanajuato es una de las entidades del país con mayor tradición migratoria, lo cual también provoca que los jóvenes aspiren a irse "al norte" con el objetivo de tener otro trabajo y obtener mejores ingresos.

Al respecto había también que matizarse que aunque cada vez disminuye el interés de jóvenes dedicados a la realización de objetos artesanales, sí se observa su participación en la comercialización del producto. Y en el caso del pan, es todavía posible encontrar a jóvenes empleados en las panificadoras elaborando este producto y dedicándose a la comercialización.

Al listado de dificultades en torno al oficio y sus hacedores, debe mencionarse el impacto que tienen los oficios artesanales en la salud de quienes lo realizan. Algunas de las afectaciones que mencionan integrantes del gremio, son: quemaduras, afectación por el humo y la harina que llegan a respirar y que, con el tiempo, afecta las vías respiratorias. También subrayan que están expuestos a lesiones por algún instrumento o herramienta de trabajo. Los dolores del cuerpo debido a la fuerza requerida y al estar de pie por tiempos prolongados ocasionan también mala circulación y la generación de varices (Acosta y Del Carpio, 2017). Consideran también que están expuestos a diversos accidentes de trabajo. Sus principales afectaciones, en la salud, indican que son: Quemaduras, daño en vías respiratorias (humo, harina y gas) y lesiones provocadas por accidentes por uso de maquinaria. Lo que pasa es que yo siento que ahí lo que se va mucho son los pulmones. (...) Por el humo y eso que expide el gas (Elia, 63 años, Acámbaro).

Respecto a la comercialización de pequeños productores, se observa que requieren a mayor información respecto a sus oportunidades de capacitación. Existe un desconocimiento, casi generalizado, respecto a los programas de apoyo y capacitación en elaboración del producto y su comercialización; un área de oportunidad al respecto es la mercadotecnia, entendida como "un proceso social y administrativo mediante el cual grupos e individuos obtienen lo que desean a través de generar, ofrecer e intercambiar productos de valor con sus semejantes" (Kotler, 2001, p. 7).

En el caso de quienes trabajan en pequeñas empresas dedicadas a la panificación, algunas de sus principales dificultades, indican quienes trabajan allí, son: los horarios de entrada (inician su jornada en la madrugada), el incremento del precio de los productos, la competencia con otros pequeños productores; respecto a la comercialización refieren que la venta ambulante representa una dificultad y también subrayan la necesidad de capacitación del sector en diferentes dimensiones. También los ya mencionados riesgos a la salud 
representan para ellos un problema importante y urgente de abordar.

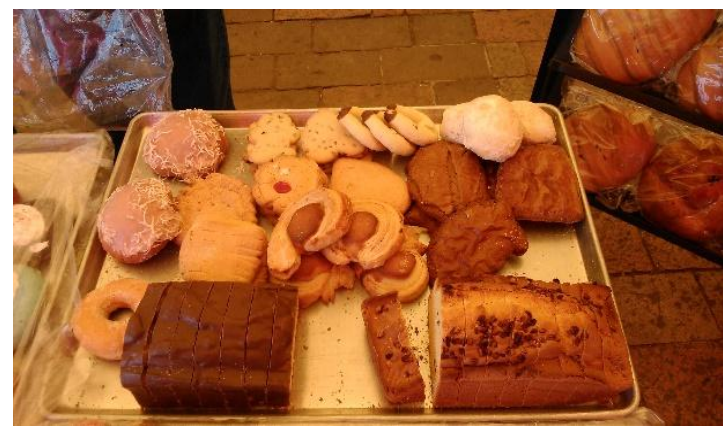

Fotografía 5. Pan dulce o fino de Acámbaro, Guanajuato

\section{Algunas estrategias}

Respecto al reconocimiento de los oficios artesanales y las artesanías, puede subrayarse que las instituciones escolares y educativas podrían promover la historia y el valor de la identidad cultural de la elaboración artesanal, esto contribuiría a la valoración y aprecio por los elaboradores y por sus productos. Sin duda, falta mucho por hacerse al respecto. La salud es prioridad, por tanto, resulta necesario también emprender acciones encaminadas a mejorar las condiciones en las que se realiza este trabajo. Es necesario crear políticas públicas y acciones encaminadas al cuidado de la salud de quienes se dedican a múltiples oficios artesanales. En el caso del pan de Acámbaro se observa que para que la comercialización de este producto incremente y para que la manera de su elaboración siga siendo peculiar, característica, diferente y única a la de panes de otros lugares, se pueden ir entretejiendo aspectos que hunden sus raíces en la tradición junto con formas innovadoras de hacer y comercializar que acudan a estrategias que se adapten a los procesos de globalización y, por ello, es importante construir rutas de marketing que mejoren la comercialización y situación de quienes se dedican a este oficio.

De acuerdo a lo que refiere el CCl y OMPI (2003), para que un negocio tenga éxito es necesario comprender y satisfacer la competencia, las necesidades y el deseo de los clientes. Esto sólo puede conseguirse si se tiene: Un producto de calidad, una marca distintiva y una comercialización eficaz.

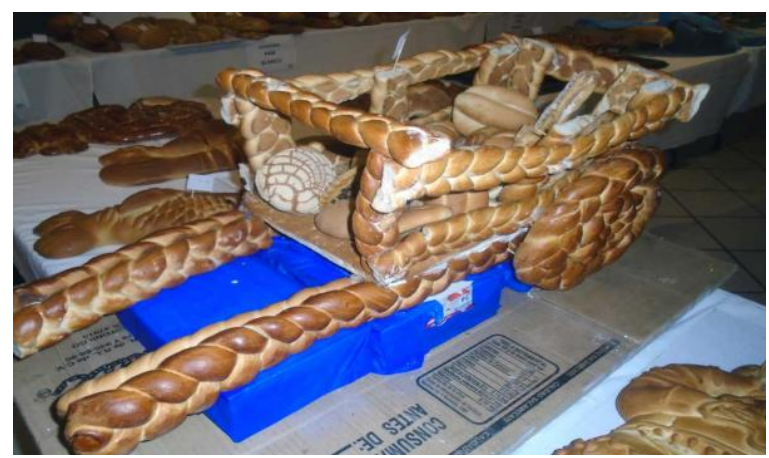

Fotografías 6 y 7 . Figuras de pan en concurso de Acámbaro. Fuente: Obtenidas en Lujano (22 de octubre de 2015).

Calificar un producto de calidad significa normalmente que el consumidor considera que este producto es mejor que los de la competencia, debido a sus atributos funcionales 0 técnicos o a su aspecto y estilo exterior. En el caso del pan, se podría hacer referencia a cualidades como: sabor, textura, consistencia, tamaño, precio y otros elementos que provienen de su manera y fórmula de elaboración. Con respecto a la comercialización eficaz de los productos, las estrategias de comercialización juegan un papel fundamental. Algunas de estas estrategias podrían proporcionarse en cursos de capacitación al gremio panadero (especialmente a los pequeños productores) y con ello fortalecer sus conocimientos respecto al uso de las tecnologías de información para visibilizar y promocionar sus productos, además de acceder a otros mercados estatales, nacionales 0 internacionales y hacer uso del servicio de paqueterías, por ejemplo.

Estos espacios también permitirían que se incrementaran las invitaciones para que participen los virtuosos de la elaboración del pan, en otros espacios: ferias o expos artesanales.

Sin duda, una de las estrategias que ha fortalecido al sector, ha sido la creación de la marca colectiva, pues, promueve una imagen de la empresa vinculada primariamente con el nombre del propietario, del negocio 0 de sus productos ( $\mathrm{CCl} \& \mathrm{OMPI}, 2003$ ). Como se ha señalado, una de las estrategias para impulsar al sector panadero en el estado de Guanajuato, ha sido la creación 
de la Marca Colectiva Pan Grande de Acámbaro Región de Origen, siendo la primera en el estado de Guanajuato.

Está conformada por 13 empresas (dato de 2016). Esta marca colectiva, dentro del concepto mercadológico, estableció altos estándares de calidad y adoptó diversos compromisos en torno al proceso: ingredientes, tiempos de fermentación, de horneo y presentación del pan. El gobernador del Estado, Miguel Márquez Márquez, entregó la marca colectiva de Pan Grande de Acámbaro Región de Origen, al grupo de empresarios guanajuatenses; respaldando nueve tipos de pan tradicional mexicano (acambaritas, pan tallado, picón, granillo, granillo de leche, ranchero, pan de muerto, cema y pan de agua) elaborados con infraestructura de calidad, de tal manera que se mantenga el auténtico sabor y aroma de las recetas tradicionales del pan artesanal, propias de esta región. El mandatario estatal también alentó a los empresarios a no descuidar la marca colectiva, a cumplir con las reglas y lineamientos establecidos, así como a mantener la calidad del producto, ya que alrededor de mil personas dependen de esta certificación industrial (Comunicación Social de Gobierno, 22 de mayo de 2014)3.

Fotografía 8: Entrega de la Marca Colectiva de Pan Grande de Acámbaro

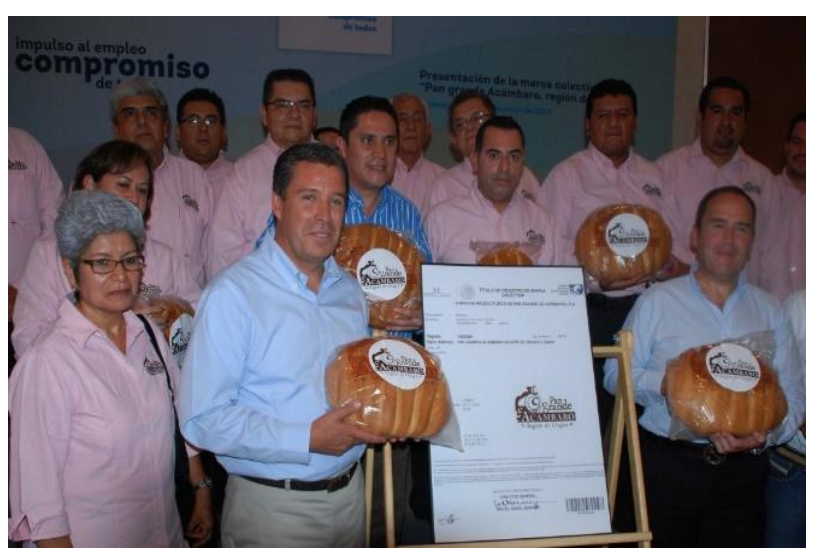

Región de Origen.

Fuente: Obtenida de Comunicación Social de Gobierno del Estado, 22 de mayo de 2014.
Para 2014 se señalaba que el $25 \%$ de la producción local de pan se quedaba en Acámbaro, el resto se comercializaba en varios municipios de Guanajuato, Estado de México, Querétaro, Michoacán, Distrito Federal, Aguascalientes y San Luis Potosí (Islas, 23 de mayo de 2014)4. Para 2016, algunas fuentes señalaban que el Estado de Guanajuato contaba con el registro de 6 marcas colectivas: Pan Grande de Acámbaro, Tequila Huanímaro Exclusivo Blanco, Sombreros San Pancho, Nopal Villa Valtierrilla, y las recién integradas: Mayólica de Dolores Hidalgo y Guanajuato y Alfarería Dolorense, todas ellas como Región de Origen. Fortaleciéndose de esa manera, un total de 940 empleos y la inclusión de 145 socios. Distinción, por medio de la cual se reconoce la calidad en el proceso de elaboración de los productos, para su incorporación a nuevos mercados comerciales (Secretaría de Desarrollo Económico Sustentable-SDES, 2016)5.

Para 2017 se indicaba que el estado de Guanajuato ocupaba el segundo lugar en el ranking nacional de marcas colectivas. $Y$ en febrero de 2018 se indicaba que en la ciudad de León se aperturaba un centro de ventas y próximamente se esperaba inaugurar otro en el aeropuerto. Esta iniciativa con el interés de posicionar la cajeta de Celaya, el pan de Acámbaro y los nopales de Valtierrilla (Periódico Correo, 10 de febrero de 2018).

Algunos de los beneficios que pueden surgir al momento de pertenecer a una Marca Colectiva de acuerdo a información presentada en El Informador (21 de enero de 2013)6, a Larios (27 de enero de 2016), a SDES (2016) y Estrategia Marca Chiapas (2016)7, se encuentran:

Es una herramienta eficaz para el posicionamiento de las artesanías.

Los productos son más conocidos en el mercado.

Los productores reciben apoyos de recursos públicos, si hay grupos organizados o bien si hay impacto en la generación de empleo.
4 Islas, L. (23 de mayo de 2014). Acámbaro y su delicioso pan que hizo historia. UN1ÓN Guanajuator Recuperado

Reconomia/otrosmunicipios/acambaro-y-su-delicioso-pan-que-hizo-historia

5 Secretaría de Desarrollo Económico Sustentable (SDES) (2016). Tiene Guanajuato dos nuevas marcas colectivas. Recuperado de http://boletines.guanajuato.gob.mx/2016/08/14/tiene-guanajuato-dos-nuevasmarcas-colectivas/

6 El Informador (21 de enero de 2013). Las marcas, factor de apoyo eficaz a las artesanías. Informador. Mx. Recuperado de http://www.informador.com.mx/economia/2013/431782/6/las-marcas-factor-deapoyo-eficaz-a-las-artesanias.htm

7 Estrategia Marca Chiapas (2016). Resultados. Recuperado de http://marcachiapas.com/se/resultados/ 
Mauricio Ortigosa Hernández

La Marca Colectiva es un signo distintivo que ayuda a identificar el origen geográfico o las características diferenciadas con respecto a otros productos similares, además de un grupo de productores.

Surge reconocimiento y protección en el ámbito internacional.

También se pueden registrar todos los derivados del producto elaborado en una región.

Se genera identidad y valor agregado, e incrementar su presencia en nuevos mercados para su competitividad.

Se logra participar en expos, ferias, diferentes eventos turísticos que visibilizan el producto $y$ aumentan las posibilidades de su comercialización.

Se puede difundir la Marca en medios masivos de comunicación.

Todo producto marcado ofrece una garantía, el consumidor tiene confianza en la marca.

El listado anterior muestra beneficios que son más difíciles de adquirir a productores que no cuentan con una marca. En este sentido, se observa que si están organizados los artesanos tienen mayores posibilidades de obtener recursos y acceder a programas de capacitación, financiamiento, adquisición, asistencia a eventos, etc. El esfuerzo individual puede ser aislado y lo que se requiere, entre otras varias cosas, es mayor organización entre los integrantes del gremio. La creación de marcas y este tipo de estrategias fortalecen la economía local a través de la creación de nuevos empleos y propicia la creación de rutas que impulsan el desarrollo de los municipios y del estado donde se realizan los mencionados productos.

\section{CONCLUSIONES}

Es indudable la importancia cultural y económica de la elaboración de pan en el municipio de Acámbaro, Guanajuato. Su producción, entre otras varias cosas, se debe a que el estado de Guanajuato es uno de los principales productores de trigo en el país. La producción de pan es un oficio que ha ido transformándose y se ha ido adaptando a las demandas del mercado y a los impulsos de globalización. En este sentido, se observa que en el municipio su elaboración es artesanal, semi-industrial e industrial. Co-existen diferentes formas de elaboración, sin embargo, incrementa la tendencia de tecnificar más la elaboración debido a la demanda del producto y a la creación de nuevos establecimientos a través de los cuales se ha ido expandiendo la comercialización del pan de Acámbaro.

En la cantidad del producto, el pequeño productor no puede competir con la industria que produce pan a gran escala, sin embargo, sí puede hacerlo desde la calidad de sus productos. Existe gran cantidad de espacios que en el municipio se oferta pan, lo cual incrementa la competencia entre productores, ello no representa afectación a la receta tradicional de elaborar el pan grande, puesto que los mecanismos que han introducido son solo de apoyo para agilizar el proceso, cuidando la permanencia de la receta tradicional. Queda claro que, en sus diferentes formas de elaboración y escala de producción, la comercialización de este producto impulsa la economía del municipio de Acámbaro. Genera empleos en el lugar y es un espacio laboral inclusivo, ya que incrementa el número de mujeres que trabajan en la elaboración y comercialización de este producto. Se dedican también personas jóvenes y mayores, sin embargo, estos últimos (los adultos) nos comparten su preocupación de que los jóvenes ya no quieran dedicarse a este oficio de antigua raigambre.

A pesar de la importancia cultural y económica de la elaboración y comercialización del pan de Acámbaro, los pequeños productores enfrentan múltiples dificultades: la competencia con la industria que produce a gran escala, la competencia desleal, la poca valoración del oficio y los ingresos que obtienen que no compensan tiempos y esfuerzos trabajo. Requieren mayor capacitación respecto a materias primas, comercialización, acceso a créditos y cuidado ante los riesgos a la salud por dedicación al oficio. Quienes trabajan en panificadoras han señalado dificultades como los horarios de la jornada de trabajo, el incremento 
del precio de los productos, la competencia con otros productores y necesidad de capacitación constante. Es valioso que desde diferentes instancias, como las del sector educativo, se promueva el conocimiento histórico y cultural de la creación de este alimento en el municipio, pues, aunque sus creadores conocen el origen de esta tradición en el municipio, existe también un desconocimiento entre los habitantes, consumidores y hasta entre los propios hacedores, especialmente entre quienes realizan el proceso industrial.

Es necesario que se sigan realizando esfuerzos conjuntos, como la creación de la Unión y de la Marca Colectiva de Pan Grande de Acámbaro Región de Origen, pues, esto seguirá permitiendo la obtención de oportunidades de apoyos y otros beneficios, los cuales son más difíciles de adquirir para productores que no cuentan con una marca o no están organizados para obtener recursos de programas de capacitación, financiamiento, adquisición, asistencia a eventos y apoyo en otros rubros. Sin duda, son múltiples las áreas de oportunidad que enfrenta todavía el gremio panadero, por ello consideramos necesario realizar investigación transdisciplinaria respecto a la elaboración, consumo y comercialización de este alimento desde el cual se fomenta el desarrollo cultural, gastronómico y económico del municipio de Acámbaro y de sus comunidades.

\section{REFERENCIAS:}

Acosta, Martha y Del Carpio, Perla (2017). Salud ocupacional: Impacto del oficio artesanal en artífices que realizan su trabajo en bipedestación prolongada. Revista Jóvenes en la Ciencia, 3 (2), pp. 397402.

Aguado, E. (12 de noviembre de 2014). Pan de Acámbaro, de madrugadas y amasijos. SomosMass99. Recuperado de http://www.somosmass99.com.mx/pande-acambaro-de-madrugadas-yamasijos/

Aguado, E. (2014). El pan de Acámbaro. Guanajuato, México: Ediciones La Rana.

Castro, E. (17 de mayo de 2016). Pan tradicional nacido en Acámbaro. AM. Consultado el 21 de abril de 2018. Obtenido de https://www.am.com.mx/2016/05/17/leon/ valor-agregado/pan-tradicional-nacidoen-acambaro-28476

Centro de Comercio Internacional UNCTAD/OMC (CCI) \& Organización Mundial de la Propiedad Intelectual (OMPI) (2003). Marketing de la artesanía y las artes visuales: función de la propiedad intelectual: Guía práctica. Ginebra, Suiza: $\mathrm{CCl} \& \mathrm{OMPI}$.

Comunicación Social de Gobierno (22 de mayo de 2014). Entrega el gobernador, Miguel Márquez, la primera marca colectiva de Pan Grande de Acámbaro, Región de Origen. Noticias Guanajuato. Obtenido de

http://noticias.guanajuato.gob.mx/2014/0 5/22/entrega-el-gobernador-miguelmarquez-la-primera-marca-colectiva-depan-grande-de-acambaro-region-deorigen/

El Informador (21 de enero de 2013). Las marcas, factor de apoyo eficaz a las artesanías. El Informador. Mx. Recuperado de http://www.informador.com.mx/economia/ 2013/431782/6/las-marcas-factor-deapoyo-eficaz-a-las-artesanias.htm

Estrategia Marca Chiapas (2016). Resultados. Obtenido de http://marcachiapas.com/se/resultados/

Islas, L. (23 de mayo de 2014). Acámbaro y su delicioso pan que hizo historia. UN1ÓN Guanajuato.

Obtenido de 
http://www.unionguanajuato.mx/articulo/2 $\underline{014 / 05 / 23 / e c o n o m i a / o t r o s-}$ municipios/acambaro-y-su-delicioso-panque-hizo-historia nuevas marcas colectivas. Obtenido de http://boletines.guanajuato.gob.mx/2016/ 08/14/tiene-guanajuato-dos-nuevasmarcas-colectivas/

Kotler, P. (2001). Dirección de Mercadotecnia: Análisis, planeación, implementación y control (8va ed.). Lima, Perú: Pearson Educación.

Larios-Gómez, E., Estrada, S., \& Luna, E. (2015). La marca ciudad Celaya como estrategia de inserción al city marketing: diagnóstico preliminar. En Contreras, R., Ruiz-Rueda, H. y Molina, R. (coord.) Ejes de crítica y reflexión en torno a la cultura y al desarrollo. México: Pearson, pp. 119137. ISBN: 978-607-32-3635-5.

Larios, X. (27 de enero de 2016). Guanajuato tendrá tres nuevas marcas colectivas. El Economista. Obtenido de http://eleconomista.com.mx/estados/2016 101/27/guanajuato-tendra-tres-nuevas$\underline{\text { marcas-colectivas }}$

Lujano, O. (01 de noviembre de 2015). Don Noé da vida al pan de muerto. Periódico Correo. Obtenido de http://periodicocorreo.com.mx/don-noeda-vida-al-pan-de-muerto/

Lujano, O. (22 de octubre de 2015). Concursan olores y sabores en Acámbaro. Periódico Correo. Obtenido de http://periodicocorreo.com.mx/concursanolores-y-sabores-en-acambaro/

Rendón, C. (10 de febrero de 2018). MM inaugura Marcas Colectivas de Guanajuato. Periódico correo.Consultado el 20 de abril de 2018. Obtenido de: https://periodicocorreo.com.mx/mmminaugura-marcas-colectivas-guanajuato/

Secretaría de Desarrollo Económico Sustentable (SDES) (2016). Tiene Guanajuato dos 